\title{
浅谈现代建筑工程中的装配式建筑施工
}

何远安

河北佳邦建设工程有限公司

DOI:10.32629/btr.v2i6.2262

[摘 要] 现代建筑工程中的装配式建筑是指工程主体构件采用装配式方式,在工厂预制以及现场拼装。并且装配式建筑具有 结构安全、施工快捷、节能省地、绿色环保、高度集约等优点,其是指全部或部分采用混凝土预制构件装配连接来形成建筑 主体的结构形式。为了保障装配式建筑工程建设的顺利进行, 本文阐述了装配式建筑工程的主要作用及其特征, 对现代建筑工 程中的装配式建筑施工要点进行了探讨分析。

[关键词] 装配式建筑; 作用; 特征; 现代建筑工程; 施工要点

随着城市建筑节能减排和可持续发展等环保政策的出 台, 装配式建筑工程的建设已成为建筑工业化的发展趋势。 为了保证施工质量, 在现代建筑工程的建筑施工中讨论和讨 论了以下几点:

\section{1 装配式建筑工程的主要作用}

预制建筑项目的主要功能是:

1.1 具有工期与成本优势的作用

传统建筑的主体结构施工完成后, 需要 1-2 个月才能挖 出窗洞, 防水, 并将子框架关闭。预制构造点使用预制的壁砖 外部窗户的预制外部壁板。主体结构加盖后, 周边可直接封 闭, 节省近两个月, 预制建筑施工点也易于预先插入室内砌 体。更早开始建筑装饰工程。此外, 在传统建筑中, 建造外墙, 隔热膏和抗裂砂浆需要 2-3 个月。相比之下, 预制建筑施工 点可用于在预制外墙和凸窗中同时制造隔热和装饰层。建筑 外部装修的时间接近 3 个月。由于施工效率高, 施工周期短, 预制房屋在施工成本上也具有很大的优势, 节省了机械和劳 动力成本, 节省了劳动力成本。无论是厂内生产还是现场组 装预制构件, 都是标准化, 标准化的流动式可重复劳动, 施工 效率更高。

\section{2 节能环保作用}

制造的建筑材料的数量较少, 并且产生较少的建筑垃 圾。预制建筑工程中使用的预制构件来自工厂加工, 建筑材 料的利用率较高, 加工车间的环境更加稳定。有助于预制构 件的质量控制, 预制构件的现场组装工作量小, 施工噪声强 度低。施工进度快, 施工对周围居民的正常生产和生活影响 较小, 施工产生的粉尘, 废水和有害物质排放较少。它还有效 地缓解了施工带来的环境问题。

\section{3 节约资源作用}

目前, 我国建设项目的建设和使用能耗远远高于发达国 家。节能建筑的建设和发展缓慢, 钢筋混凝土结构的使用范 围广泛, 造成一定的资源浪费。施工过程中也造成了一定的 污染, 资源利用率不高。相比之下, 预制建筑项目的建设是工 业化和模块化的, 以更好地保护环境。建筑和使用的能耗较 低, 这可以改变中国建筑的高能耗。外墙不需要现场浇筑施
工, 外墙模板使用较少, 应用层压阳台也有效地解决了木材, 钢材和混凝土的使用问题。能够节约 40\%的木材。

\section{2 装配式建筑工程的主要特点}

预制建筑项目的特点主要有:

2.1 设计多样化

预制建筑采用大型开放空间之间的灵活分割, 可根据居 民的需要分为小厅和小厅。房子的核心问题之一是柔性轻质 隔断, 带有石膏板或其他光板的轻钢龙骨是隔板和天花板的 最佳材料。

\section{2 制造工厂化}

预制建筑外墙板采用模具, 机械喷涂, 烘烤工艺制造; 屋 顶桁架, 轻钢龙骨, 各种金属吊挂及连接件等均为机械化生 产; 在工厂的生产过程中, 可以随时控制材料的性能, 如强调, 耐火, 抗冻融, 而火, 防潮, 隔音等性能指标。

\section{3 施工装配化}

由于组装建筑物的自身重要性减少了传统建筑物重量 的一半, 因此基础也得以简化。在工厂的预制建筑构件出厂 后, 现场工人将按照地图进行组装, 过去的大面积潮湿, 泥浆, 抹灰和墙体建筑将永远不会在施工现场发生。

\section{4 功能现代化}

第一、节能。外墙有一层保温层, 可最大限度地提高冬 季采暖和夏季空调的能耗; 第二、隔声。提高墙体和门窗的 密封性能, 绝缘材料具有吸音功能, 避免外界噪声干扰; 第 三、抗震。使用大量轻质材料来减轻建筑物的重量并增加组 件的灵活连接; 第四、防火。使用不可燃或不可燃材料, 以 防止火势蔓延或蔓延。

2. 4. 1 预制构件施工要点主要表现为:

(1) 合理制定模具方案。模具计划的制定应考虑工艺的 合理性, 模具的利用率和生产效率。预制模具可分为普通模 具和特殊模具。普通模具, 即相同类型的部件共用一套模具 生产, 通过将侧模安装在不同的齿轮位置, 可以实现不同尺 寸的部件, 模具利用率高; 特殊模具是每个部件的一组模具, 不能与其他部件共用, 模具利用率低。模具解决方案通常根 据组件的结构形式确定: 平板部件相对容易实现多部件共模, 
并且使用更常见的模具, 而通常使用异形部件。但是, 在确定 模具计划时, 还需要结合实际项目的类型, 数量和施工进度 要求。(2) 预埋预留施工要点分析。组装好的组件中有许多 预制组件, 主要类型有: 吊件、连接件、窗框、管线等。大 部分构件还有预留孔洞或沟槽等。当组件预制时, 这些嵌入 部件的定位和保留应该是准确的, 否则在后面的组装和构造 中难以调整。嵌入式吊架和连接件大多为圆柱形, 带有内螺 纹, 尾部设有横向肋, 以加强与混凝土的针固。预嵌入的悬挂 器和连接构件通常布置在构件的光接收表面上, 并且构件由 固定在侧模具上的悬臂框架预先形成。嵌入式门窗框架一般 应固定在底模上, 并采取保护措施防止框架表面被污染。使 用铝制窗扇时, 必须采取措施避免铝框架与混凝土直接接触 的电化学腐蚀。预埋管道, 箱体等在混凝土凝固前应承受浮 力, 固定应牢固可靠, 避免位置偏差。另外, 当混凝土振动时, 要求混凝土杆不能接触嵌入部分, 以避免损坏或浆液。预留 的孔和槽主要通过模具形成, 并且模具部件需要精确安装。

(3) 夹层保温板预制施工点分析。墙板由两层钢筋混凝土和 隔热三明治组成, 称为夹层隔热墙板。根据两层钢筋混凝土 是否独立承受载荷, 夹层保温板分为组合墙板和非组合墙 板。复合墙板的内层和外层共同加载并具有高刚性。技术要 求较高。非组合墙板的双层混凝土独立加载, 刚度低, 但内外 两层混凝土可以独立变形, 不受温度应力损坏。目前, 中国使 用更多的非组合墙板。

2.4 .2 吊装定位施工要点分析

用于装配和施工的主要起重工具包括起重钢梁, 连接件, 索具等。多组吊耳对称设置在提升钢梁上, 以适应不同部件 的提升距离。连接器用于连接部件和索具, 主要由底座, 安装 孔, 螺栓等组成。构件吊装工序为: 入口检查-编号-适配器 的安装-提升钢梁的连接-提升-钢筋对准-着陆位置-调整到 位。组件吊装到位后, 底部应设置限位装置, 并设置可调节支 撑作为临时支撑系统。在现浇混凝土或接缝的灌浆能力达到 设计要求后, 必须移除力传递的部件。在吊装和定位过程中, 应保护单个预制构件免受大负荷的影响, 并应避免使用受力 模式。

2.4. 3 受力钢筋间连接施工要点分析
在制造的剪力墙结构和制造的框架-剪力墙结构中, 预 制剪力墙和预制剪力墙的水平节点预制框架柱节点的纵向 加固主要通过套筒灌浆连接和约束浆料针固连接来连接。第 一、套筒灌浆连接。套筒灌浆连接是一种连接技术, 其依赖 于灌浆在套管中的针固作用以及钢筋的针固以连接钢筋。灌 浆套筒嵌入部件的纵向加强钢筋的底端, 下层部件上部的向 外延伸的纵向肋在组装和构造过程中插入预埋套筒中。然后 施加灌浆并施加一定的压力以用灌浆填充空腔并适当地保 持。目前常用的灌浆套管有两种类型的完全灌浆和半灌浆接 头套管。半灌浆套管的一端固定, 另一端机械连接。第二、 约束浆针连接。受约束的浆料针固连接不使用套管, 并且直 接取决于混凝土的锚固作用和连接的钢筋上的灌浆。波纹孔 保留在构件底端的纵向肋附近, 并且这些段用螺旋肋加强。 在组装和构造期间, 下层上部的向外延伸的纵向肋插入孔中, 压力灌浆并适当地保持。

2.4. 4 通过混凝土后混凝土连接分析构件的施工点

预制剪力墙, 预制梁柱节点, 预制梁柱节点和结构预制 构件与现浇现浇部分之间的连接通常通过后浇混凝土连接。 接头处的部件表面应在预制过程中进行粗糙化处理 (可刷涂 或延迟）。在浇注混凝土之前, 清洁组件的接头并用水润湿。 后浇混凝土需要一次浇铸, 应注意模板不能泄漏。

\section{3 结束语}

综上所述, 科技的进步发展提高了装配式建筑施工技术 水平, 其通过预制建筑结构件, 可以提高现场施工效率、控制 施工成本以及提高施工质量, 因此必须加强对现代建筑工程 中的装配式建筑施工进行分析, 从而促进建筑业的健康发展。

\section{[参考文献]}

[1] 郭章林.浅谈装配式建筑的发展[J].价值工程,2017(1):46.

[2]黄国知.简议装配式建筑混凝土结构工程施工技术要 点[J].装饰装修天地,2017(24):67.

[3]王桂生.装配式建筑施工技术在建筑工程施工管理中 的应用 [J].工程建设与设计,2017(21):175-176.

[4]张海峰.装配式建筑机电工程施工技术研究[J].建材 与装饰,2019(15):39-40. 